\title{
La conformidad con los derechos humanos y la equidad de los acuerdos amistosos ante el Tribunal Europeo de Derechos Humanos
}

\author{
Compliance with Human Rights and Equity of Friendly \\ Settlements Before the European Court of Human Rights
}

BRIAN BUCHHALTER MONTERO ${ }^{1}$

Resumen: El autor analiza la regulación actual de los acuerdos amistosos ante el Tribunal Europeo de Derechos Humanos. El punto más conflictivo de su regulación es la nebulosa cláusula de respeto por los derechos humanos que, en la práctica, no ha sido clarificada por la jurisprudencia del Tribunal.

Palabras clave: justicia convencional, Convenio Europeo de Derechos Humanos, Tribunal Europeo de Derechos Humanos, mecanismos alternativos de resolución de conflictos, mediación.

Abstract: This paper analyzes the current regulation of friendly settlements before the European Court of Human Rights. The most conflictive point in its regulation is the nebulous clause of respect for human rights which, in practice, has not been clarified by the Court's jurisprudence.

Key words: conventional justice, European Convention on Human Rights, European Court of Human Rights, alternative dispute resolution mechanisms, mediation.

\footnotetext{
${ }^{1}$ Estudiante de quinto curso del Doble Grado en Derecho y Ciencias Políticas de la Universidad de Valencia. Becario de colaboración de la Universidad de Valencia, Departamento de Derecho Procesal y Administrativo.
} 
Recibido: 26.8.2020 Aceptado: 26.11.2020

\section{Sumario}

1. Introducción

2. Conformidad con los derechos humanos: Una revisión de los criterios

3. Naturaleza jurídica del control de conformidad: Regla

4. Anclaje normativo de la conformidad con los derechos humanos

5. Justificación de la distinción entre criterios de conformidad propia e impropia

6. Estructura actual de los criterios de conformidad

7. Reestructuración de los criterios de conformidad con los derechos humanos

a. Conformidad propia o justificación convencional interna

b. Conformidad en sentido amplio

c. Recapitulación

8. Equidad del acuerdo

9. Conclusiones

\section{Introducción}

Los mecanismos alternativos de resolución de conflictos despiertan el interés de estudiosos y operadores jurídicos de todas las jurisdicciones, pues evitan el largo y costoso proceso judicial, a la vez que producen satisfacciones rápidas y eficaces. Estos mecanismos son especialmente populares en los litigios civiles y comerciales, para cuya resolución son especialmente adecuados. Sin embargo, los 
problemas se agudizan cuando los mecanismos alternativos de resolución de conflictos se emplean en supuestos de vulneraciones a veces muy graves - de derechos humanos. El propósito de este trabajo es ahondar en la virtualidad de los mecanismos amistosos de resolución de conflictos en el marco de la justicia convencional. Para ello, este estudio centrará su atención en el artículo 39.1 del Convenio Europeo de Derechos Humanos (CEDH, en adelante). El precepto establece lo siguiente:

(e)n cualquier fase del procedimiento, el Tribunal podrá ponerse a disposición de las partes interesadas para conseguir un acuerdo amistoso sobre el asunto inspirándose para ello en el respeto a los derechos humanos tal como los reconocen el Convenio y sus Protocolos.

En este sentido, los acuerdos amistosos deben ser conformes con los derechos humanos, tal como son concebidos por el CEDH y los Protocolos (arts. 37.1 in fine en relación con el art. 39.1 CEDH y el art. 62.3 del Reglamento del Tribunal Europeo de Derechos Humanos, en adelante RTEDH); y, a su vez, deben ser "equitativos”, como señala el art. 75.4 RTEDH. Qué es tal “conformidad” o "equidad” no es del todo claro, especialmente porque el art. 39.3 CEDH no obliga al Tribunal a motivar su decisión, ni a exponer la aplicación de los criterios de conformidad con los derechos humanos. El precepto permite al Tribunal archivar el asunto "mediante una decisión que se limitará a una breve exposición de los hechos y de la solución adoptada" (art. 39.3 CEDH). El art. 39.3 CEDH es, por tanto, una excepción al deber general de motivación de las resoluciones del art. 45.1 CEDH. Ello ha suscitado justificadas críticas, pues podría suceder que el TEDH estuviera "minimizando su actividad de asegurarse que los acuerdos se basan en el respeto por los derechos humanos, especialmente en los casos en los que el Estado demandado no admite responsabilidad alguna" (WEBER, 2007, pág. 235). El abuso de los acuerdos amistosos comporta el peligro de que el Tribunal mute paulatinamente hacia "un foro de negociaciones", en detrimento de su genuina función de 
definición y protección de los derechos humanos (KELLER, FOROWICZ, \& ENGI, 2010, pág. 85).

\section{Conformidad con los derechos humanos: Una revisión de los criterios}

La conformidad con los derechos humanos es la piedra angular de todo el mecanismo alternativo de resolución de conflictos. Suprimida esta, los ya nebulosos límites objetivos de la institución se disolverían, en perjuicio de demandantes desesperados por satisfacciones rápidas, pero en beneficio de Estados poco preocupados por la "paz jurídica" y de un Tribunal ya saturado de trabajo. A pesar de la relevancia de los criterios de conformidad, la verdad es que predomina cierta confusión, tanto sobre su contenido, como sobre su base legal. Esta confusión se manifiesta en la disparidad de criterios legales que sustentan las decisiones del Tribunal sobre la materia.

La necesidad de aclarar el sustrato legal y los criterios sobre los que el Tribunal se basa para declarar la conformidad con los derechos humanos es acuciante. Sin embargo, antes de analizar la base y estructura del canon de conformidad, debe diferenciarse entre un control ex ante y un control ex post (KELLER, FOROWICZ, \& ENGI, 2010, pág. 30). Sobre el control ex ante, sirva tan solo señalar que desempeña una función preventiva muy relevante, pues si las partes, exentas de todo control, alcanzan un acuerdo amistoso por sí mismas, el peligro de abuso es inherente (KELLER, FOROWICZ, \& ENGI, 2010, pág. 30). Por ello, mientras el Tribunal y la Secretaría ayudan a alcanzar el acuerdo amistoso, realizan - in itinere - un control de conformidad con los derechos humanos, es decir, una suerte de asesoría, que asegura o incentiva a las partes a respetar los derechos humanos. Muestra de la efectividad de este control ex ante es que nunca se ha dado que la antigua Comisión rechazara un acuerdo amistoso, pues esta ya "habrá defendido el interés general en un momento previo, haciéndolo característica de las negociaciones 
desde un muy temprano comienzo" (KRÜGER \& NØRGAARD, 1988, pág. 332). Tampoco se excluye de este control $e x$ ante a las partes mismas, que en un ejercicio de "autocontención" evitan cualquier cláusula que pueda ser irrespetuosa con los derechos humanos. Ahora bien, el control principal que a este trabajo ocupa es el ex post, es decir, el que se produce una vez alcanzado el acuerdo, y en el que ya no intervienen ni la Secretaría ni las Partes, sino tan solo el Tribunal.

\section{Naturaleza jurídica del control de conformidad: Regla}

Aclarado que este estudio tan solo se ocupa del control expost, la primera cuestión que se plantea es la determinación de la naturaleza misma del canon. La tesis que se defiende en este trabajo es que la conformidad con los derechos humanos no es un principio, sino una regla. Como ha señalado ALEXY,

(I)as reglas son normas que exigen definitivamente algo. Son imperativos definitivos. Se aplican a través de la subsunción. Por el contrario, los principios son normas, que exigen que algo se realice en la mayor medida posible, conforme a las posibilidades fácticas y jurídicas existentes. En consecuencia, los principios son imperativos de optimización [Optimierungsgebote] y la forma de su aplicación es la ponderación (ALEXY, 2015, pág. 204).

Los principios son normas jurídicas que admiten, dentro de su observancia, diferentes subgrados de cumplimiento. Las reglas, por el contrario, no admiten tales subgrados. Se cumplen o no se cumplen. Así, entender la conformidad con los derechos humanos como una regla tiene una repercusión fundamental en la estructura de los criterios de aplicación de conformidad en sentido estricto: este habrá de estar construido solo por elementos normativos. Por el contrario, la conformidad en sentido amplio podrá abarcar consideraciones fácticas o externas, ajenas al sistema normativo del CEDH. 


\section{Anclaje normativo de la conformidad con los derechos humanos}

La conformidad con los derechos humanos es tratada, con distinta intensidad, por los arts. 37.1 in fine, 39.1 CEDH y 62.3 RTEDH. El primero de estos preceptos señala que "el Tribunal proseguirá el examen de la demanda si así lo exige el respeto de los derechos humanos garantizados por el Convenio y sus Protocolos" (énfasis añadido). Aquí se debe aclarar cuál es la relación entre el art. 39.1 $\mathrm{CEDH}$ - antes transcripto-y este 37.1 CEDH in fine.

En este sentido, hay quienes defienden que el art. 37.1 CEDH no sería de aplicación para los acuerdos amistosos, pues estos disponen de su lex specialis (art. 39.1 CEDH) (KARPENSTEIN, MAYER, \& WENZEL, 2015, art. 39, par. 1-3). Algunos autores afirman que, para aprehender la esencia del canon de conformidad, habría de tenerse en consideración tan solo los arts. 39.1 CEDH y 62.3 RTEDH (o, por lo menos, dar al art. 37.1 CEDH un papel meramente informador). Sin embargo, la tesis de la especialidad del art. 39.1 CEDH, frente a la generalidad del art. 37.1 $\mathrm{CEDH}$, nos conduce a la insatisfactoria conclusión de que existirían dos cánones de conformidad con los derechos humanos: uno para los acuerdos amistosos (art. 39.1 CEDH) y otro, presumiblemente más exigente, para todo el resto de los supuestos que prevé el art. 37.1 $\mathrm{CEDH}^{2}$

En contraposición, una interpretación teleológica de ambos preceptos nos conduce a entender que la mayor virtualidad de los derechos humanos (télos del $\mathrm{CEDH}$ ) exige el canon más severo posible, de manera que la relación que rige entre los arts. 37.1 y 39.1 $\mathrm{CEDH}$ no es de especialidad (y de exclusión, por tanto) sino de complementariedad. Así, la más estricta exigencia de respeto por los

\footnotetext{
${ }^{2} \mathrm{Y}$ es que, ad absurdum, una interpretación literal del art. 39.1 CEDH no permitiría, ni siquiera, deducir un canon de conformidad con los derechos humanos, pues a lo que se refiere el precepto es que el TEDH se pondrá a disposición de las partes "inspirándose para ello [la Corte y no el acuerdo] en el respeto a los Derechos Humanos tal como los reconocen el convenio y sus protocolos".
} 
derechos humanos del art. 37.1 CEDH se proyecta también sobre los acuerdos amistosos del art. 39.1 CEDH. Por tanto, ambos preceptos no se excluyen, sino que se complementan, formando un régimen jurídico unitario. Una interpretación sistemática arroja el mismo resultado: la armonía entre ambos preceptos se manifiesta en el art. 43.3 - frase primera- RTEDH, donde ambos aparecen mencionados conjuntamente como fenómenos de la misma naturaleza. Tampoco la práctica del TEDH asume una relación de especialidad entre ambos preceptos, pues los acuerdos amistosos son en muchos casos autorizados por la vía de los arts. 37.1.b) y 37.1.c) CEDH sin distinción alguna (ABDELGAWAD, 2018, pág. 13). La conclusión, que de todo ello debe extraerse, es que tan solo existe un canon de conformidad con los derechos humanos, y que su naturaleza es la de las reglas.

Asumida esta conclusión, la siguiente tarea es (re)construir los criterios de conformidad de acuerdo a su naturaleza de regla, lo que implica que el canon en sentido estricto tan solo incorporará elementos normativos derivables del sistema del CEDH. Sin embargo, esto no significa que, en la decisión final sobre la conformidad, no tengan un rol importante otras consideraciones, externas al $\mathrm{CEDH}$, pues como se ha dicho: "uno no debe considerar los acuerdos amistosos solo desde la perspectiva de la legalidad, sino también desde la perspectiva de la moralidad" (KELLER, FOROWICZ, \& ENGI, 2010, pág. 85). ${ }^{3}$ La conformidad en sentido estricto, sí debe nacer del propio Convenio, pues así lo exige —además de su naturaleza de regla - el tenor literal del art. 39.1, en relación con el art. 37.1 in fine CEDH. ${ }^{4}$ Por todo ello — como se va a exponer ahora-, es necesario

\footnotetext{
${ }^{3}$ La misma tesis sostiene ZWAAK al señalar que "este método [el de los acuerdos amistosos] no está basado necesariamente en consideraciones únicamente legales; otros factores pueden tener un rol en el” (ZWAAK, 2006, pág. 222).

${ }^{4}$ Sirva para aclarar que no pueden identificarse las consideraciones normativas con las de oportunidad. Así, "por ejemplo, se puede decir que la validez en el sentido normativo corresponde a la eficacia de la norma en el sentido sociológico, pero no a la definición de una por la otra. No se puede definir el 'debería', la obligación del deudor de cumplir y el derecho del acreedor a exigir, mediante expresiones del ámbito de los hechos, como la expectativa (de una sanción) o la facultad (de ejecutar), aunque una tienda a estar
} 
distinguir entre un canon (o conjunto de criterios) de conformidad propio, que abarca aspectos exclusivamente jurídico-convencionales, y un canon de conformidad impropio, que abarca consideraciones fácticas o de oportunidad, externas al Convenio.

\section{Justificación de la distinción entre criterios de conformidad propia e impropia}

La reformulación de estos criterios de conformidad con los derechos humanos exige una justificación más. Nos servimos del canon que el Tribunal Constitucional alemán emplea para valorar si existe una vulneración de un derecho fundamental, pues sirve de base, como se verá, para explicar la estructura de la conformidad con los derechos humanos. El Alto Tribunal alemán afirma que existe una vulneración de un derecho fundamental cuando: a) el ámbito personal y material de protección del derecho fundamental está abierto (Eröffnung des Schutzbereichs); b) cuando existe una intromisión por parte del Estado en el ámbito de protección (Eingriff), y c) cuando la intromisión no está constitucionalmente justificada (verfassungsrechtliche Rechtfertigung), es decir, cuando la antijuricidad de la intromisión no está excluida. ${ }^{5}$ La consideración del canon de conformidad con los derechos humanos como regla, despliega su relevancia en el ámbito de la justificación constitucional (convencional, para en el caso del CEDH). En este sentido, de lo que se trata es de comprobar si el acuerdo amistoso está justificado —está excluida su antijuricidad-.

Respecto de la justificación constitucional, KLATT y MEISTER han realizado una sagaz diferenciación entre justificación constitucional interna y justificación constitucional externa (KLATT \&

relacionada con la otra, porque ambas no significan lo mismo" (énfasis añadido) (LARENZ \& CANARIS, 1995, pág. 23).

${ }^{5}$ Art. 93.I. núm. 4 de la Ley Fundamental de la República Federal Alemana $(G G)$, \$\$ 13 núm. 8a 90 y ss. de la Ley del Tribunal Constitucional Federal Alemán ( $B V \operatorname{Verf} G G$ ). También al respecto, véase EPPING (EPPING, 2019, pág. 77 y 105 y ss.). 
MEISTER, 2014, pág. 195). La primera es neutral, de manera que se puede aplicar universalmente, y solo se ocupa de comprobar que, dentro del sistema construido por la norma, ${ }^{6}$ la afectación está justificada, es decir, que la antijuricidad queda excluida. Esta justificación constitucional interna es extrapolable al CEDH. Con ella se identifica la conformidad en sentido estricto. La justificación externa, por el contrario, depende de factores distintos de la norma jurídica con la que se contrasta la afectación.

Sin embargo, la tesis de KLATT y MEISTER, que ofrece una muy importante base para la conformidad, no es aceptable por el siguiente motivo: la justificación como exclusión de la antijuricidad exige necesariamente un contenido jurídico. Es decir, el ordenamiento jurídico es el que levanta la prohibición de realizar una acción o el que afirma que tal acción está permitida. Sobre la base de esta consideración, se entiende que la justificación o el permiso, necesariamente, debe venir del ordenamiento jurídico y no de factores externos, de lo fáctico (LARENZ \& CANARIS, 1995, pág. 21). ${ }^{7}$ De esta manera, no es posible hablar de una "justificación externa" al Convenio (ni a ninguna norma jurídica). No obstante, esta distinción que realizan KLATT y MEISTER entre un ámbito externoy otro ámbito interno de la justificación es plenamente aprovechable. La conformidad con los derechos humanos se puede construir igualmente respetando esta división bipartita, pero con una denominación diferente y acorde a la naturaleza de la justificación.

Por todo ello, como se ha señalado anteriormente, es necesario distinguir entre un canon de conformidad propio (que abarca aspectos exclusivamente jurídico-convencionales) y un canon de conformidad impropio (que abarca consideraciones fácticas o de oportunidad, externas al Convenio).

\footnotetext{
${ }^{6}$ El CEDH, el RTEDH y la jurisprudencia del TEDH, para este trabajo.

${ }^{7}$ La teoría del Derecho penal se ha ocupado muy especialmente de ello. Véase, por ejemplo, MIR PUIG (MIR PUIG, 2016, págs. 157 y ss., 429 y ss.).
} 


\section{Estructura actual de los criterios de conformidad}

Expuesta la estructura del canon de conformidad, es el momento de analizar los criterios de que se sirve, in concreto, el TEDH, para juzgar la conformidad de tales acuerdos. Como se ha dicho antes, el TEDH ha sido vacilante en su jurisprudencia al respecto. En este sentido, en alguna ocasión el Tribunal ha identificado el respeto por los derechos humanos con el ordre public ${ }^{3}$ o con la comprobación "de cuestiones de carácter general que afectan a la observancia del Convenio" (ABDELGAWAD, 2018, pág. 22). ${ }^{9}$ Sin embargo, otras resoluciones han sido más concretas al exponer los criterios sobre los que puede basarse el canon de conformidad. Este trabajo toma como base los criterios expuestos para las "declaraciones unilaterales" en la sentencia recaída en el caso Acar v. Turkey(demanda núm. 26307/95, 6 de mayo de 2003), que son los siguientes: ${ }^{10}$ a) la naturaleza de las impugnaciones realizadas; b) si las cuestiones planteadas son comparables a otras ya resueltas por el TEDH; c) la naturaleza y alcance de las medidas adoptadas por el Estado demandado en el contexto de la ejecución de otras sentencias dictadas en casos anteriores, y el impacto de tales medidas en el caso en cuestión; d) si los hechos son controvertidos para las partes y, de ser así, a qué se extienden y qué credibilidad tienen a priori las alegaciones de las partes; e) la existencia o no de prueba practicada ante el TEDH, y f) si el Estado demandado ha reconocido la vulneración en su declaración unilateral (o en el acuerdo amistoso) y, si lo ha hecho, cuál es el alcance de tales admisiones y cómo pretende repararlas.

\footnotetext{
8 Sutherland V. United Kingdom, demanda núm. 25186/94, 27 de enero de 2012. También la antigua Comisión partía de consideraciones similares. Véase KRÜGER H.C. y NØRGAARD C.A., (KRÜGER \& NØRGAARD, 1988, pág. 331 y 332).

${ }^{9}$ Véase, además, Zuyev v. Russia, 14 de febrero de 2012 (demanda núm. 21302/10).

10 Véase, además, Oleksiw v. Germany (demanda núm. 31384/02, 11 de septiembre de 2007), Hassdenteufel v. Germany (demanda n 21214/03, 6 de noviembre de 2007) y Jeronovics v. Latvia (demanda núm. 547/02, 1 de Julio de 2009).
} 
Hechas estas consideraciones, salta a la vista que algunos de estos criterios no pueden ser asumidos desde una justificación interna, en la medida en que, intrínsecamente, exigen tener en consideración aspectos externos. Se hace necesario, por tanto, sin desconocer el valor de estos criterios desde una perspectiva externa, reestructurar el canon de conformidad, a efectos de compatibilizarlo con la letra y el espíritu del CEDH.

\section{Reestructuración de los criterios de conformidad con los derechos humanos}

Como se ha dicho, el canon en sentido amplio se construye por dos partes: un canon de conformidad propio (justificación convencional interna) y un canon de conformidad impropio.

\section{a. Conformidad propia o justificación convencional interna}

La justificación convencional interna supone la exclusión de la antijuricidad de la vulneración del derecho humano. La exclusión de la antijuricidad, necesariamente, debe producirse - a diferencia de la oportunidad o conveniencia del acuerdo- con base en elementos normativos presentes en sistema del CEDH. Sobre esta base, para poder afirmar que un acuerdo no es antijurídico a la luz del Convenio y sus Protocolos, deben tratarse los siguientes puntos.

- El primer asunto para considerar es si el derecho humano en cuestión es susceptible o no de transacción, es decir, “¿dónde está la línea roja?” (ABDELGAWAD, 2018, pág. 14). La respuesta no está exenta de debate y depende del derecho humano que sea vulnerado. Algunos autores proponen, con razón, que los acuerdos amistosos sobre los arts. 2 y $3 \mathrm{CEDH}$ queden excluidos a radice, pues "ciertas violaciones de los derechos humanos se consideran tan graves que la sociedad las califica de criminales. La sanción de esos delitos no constituye una restitución a la víctima [o no tan solo] (...), sino que impone castigos al autor y 
restricciones para evitar la repetición del delito" (KELLER, FOROWICZ, \& ENGI, 2010, pág. 95) ${ }^{11} \mathrm{Si}$ el CEDH tiene como finalidad conseguir la mayor virtualidad posible de los derechos humanos de los ciudadanos (y el derecho a la vida es presupuesto elemental de todos ellos), el TEDH debería llegar al fondo del asunto en los supuestos en que tales vulneraciones presuntamente se han producido y, muy especialmente, cuando se trata de violaciones sistémicas (GRABENWARTER \& PABEL, 2016, par. 70). Existen pocas declaraciones del TEDH respecto de los acuerdos amistosos sobre los arts. 2 y 3 CEDH. Sí se pronunció en dicho sentido, por ejemplo, en el asunto Surmanidze v. Georgia (demanda núm. 11323/08, 24 de junio de 2014) al señalar que: "el carácter fundamental del artículo 2 de la Convención exige siempre que haya alguna forma de investigación oficial efectiva cuando las personas hayan resultado muertas como consecuencia del uso de la fuerza por, entre otros, agentes del Estado". ${ }^{12}$ En relación con España, el supuesto más famoso de un acuerdo amistoso en relación con los arts. 2 y 3 CEDH es el del caso Díaz Ruano (demanda núm. 16988/90, 26 de abril de 1994). Allí se acordó el pago ex gratia de 6 millones de pesetas (36.000 euros) al demandante, padre de un joven de 21 años que murió de un disparo en la cabeza en las dependencias de la policía de Telde (Gran Canaria), tras una confusa discusión. Después de agotar la vía interna, la cuestión llegó a la Comisión, ante la cual se acordaron los términos del arreglo amistoso. La Comisión admitió el acuerdo y declaró no haber percibido "ninguna razón

11 Véase, también, KARPENSTEIN, MAYER y WENZEL (KARPENSTEIN, MAYER, \& WENZEL, 2015, par. 1-3), GRABENWARTER y PABEL (GRABENWARTER \& PABEL, 2016, par. 70), y CONTESSE (CONTESSE, 2019).

${ }^{12}$ En Chkotua and Arkania v. Georgia (demanda núm. 60909/08, 25 de mayo de 2014), el TEDH afirmó “que el carácter fundamental del artículo 2 del Convenio exige que se realice algún tipo de investigación oficial efectiva para esclarecer la causa de la muerte de un recluso que había sufrido una enfermedad grave en la prisión, así como la posible falta del tratamiento médico necesario (...)." También en Baghashvili v. Georgia (demanda núm. 5168/06, 18 de marzo de 2014) y en Kiziria v. Georgia (demanda núm. 4728/08, 11 de marzo de 2014). 
de orden público que se opusiera a dar por sobreseído el caso". ${ }^{13}$ Como se ve, la Comisión también identificaba en cierta medida la conformidad con los derechos humanos con el "orden público".

Las vulneraciones de los arts. 2 y 3 CEDH exigen muy especialmente una respuesta apropiada, responsabilidad última y exclusiva del TEDH (KELLER, FOROWICZ, \& ENGI, 2010, pág. 95). Algunos países, como Turquía, están especialmente concernidos por estas consideraciones, pues las estadísticas señalan que el $17,5 \%$ de los acuerdos que concluyó Turquía en el período 1998 a 2008 se refieren a violaciones de los arts. 2 y 3 del $\mathrm{CEDH}$, lo que no conduce a mejorar la virtualidad de los derechos humanos en el país (KELLER, FOROWICZ, \& ENGI, 2010, pág. 117). ${ }^{14}$

Otros autores se oponen en fuertes términos al análisis de una demanda en contra de la voluntad de las partes (incluso en los supuestos de los arts. 2 y $3 \mathrm{CEDH}$ ): “en nuestra opinión es inconcebible que la Comisión pueda considerar que un caso particular es tan serio que no puede ser resuelto por un acuerdo amistoso, sino que debe terminar con un fallo (...) en cuanto al fondo" (KRÜGER \& NØRGAARD, 1988, pág. 332). Esta postura no es aceptable. La especial perturbación que producen para la paz jurídica, tanto nacional como internacional, las vulneraciones a los arts. 2 y $3 \mathrm{CEDH}$, debe excluir la posibilidad de transigir sobre ellos. Aquí está, a nuestro juicio, la línea roja. Como se ha sostenido, la ponderación de los intereses en juego arroja la conclusión de que el interés objetivo de la comunidad prevalece

\footnotetext{
13 Recientemente Kevei v. Hungary (demanda núm. 24405/17, 28 de mayo de 2020). También ver Sur v. Turkey (demanda núm. 21592/93, 3 de octubre de 1997); N.Ö v. Turquía (demanda núm. 33234/96, 17 de octubre de 2002); Matthews v. United Kingdom (demanda núm. 24833/94, 18 de febrero de 1999.

14 Véase, también, Haran v. Turkey (demanda núm. 25754/94, 26 de marzo de 2002), Orak v. Turkey (demanda núm. 24936/94, 10 de julio de 2001), Tatete v. Switzerland (demanda núm. 41874/98,18 de noviembre de 1999).
} 
por sobre el interés del demandante y del Estado en terminar el proceso. Así, “en los supuestos de las más graves vulneraciones de derechos humanos, el proceso debe continuar en razón de la función objetiva de protección jurídica del Convenio" (KARPENSTEIN, MAYER, \& WENZEL, 2015, par. 15). ${ }^{15}$ Esta es la práctica que sostienen la Corte y la Comisión Interamericanas de derechos humanos [Velásquez Rodríguez vs. Honduras (26 de junio de 1989)]: "la Comisión sostiene que los derechos a la vida (art. 4), al trato humano (art. 5) y a la libertad personal (art. 7), violados en el presente caso, no pueden ser efectivamente restablecidos por la conciliación; (...) la Corte entiende que el manejo del acuerdo amistoso por parte de la Comisión no se puede reprochar".

Al margen de los supuestos de los arts. 2 y $3 \mathrm{CEDH}$, existen otros casos menos problemáticos en los que la admisibilidad del acuerdo parece más indicada, como por ejemplo el derecho a la propiedad (art. 1 del Protocolo núm. 1 al CEDH). ${ }^{16}$ Así, parece más sencillo llegar a un acuerdo donde "tan 'solo' está involucrado dinero” (KRÜGER \& NØRGAARD, 1988, pág. 330).

- La segunda cuestión que se plantea es si el acuerdo se fundamenta en un consentimiento libre e informado o no, como exige su naturaleza contractual (KELLER, FOROWICZ, \& ENGI, 2010, pág. 95). El acuerdo no podrá ser respetuoso con los derechos humanos si no ha sido concluido en una atmósfera de libertad e información suficiente. La cuestión es relevante en relación con el demandante, ya que, difícilmente se puede imaginar supuestos en los que el demandante presiona al Estado para concluir un acuerdo. La libertad supone la inexistencia de

\footnotetext{
${ }^{15}$ Sobre el derecho a la igualdad en el marco internacional puede verse CUCARELLA GALIANA (CUCARELLA GALIANA, 2019)

${ }_{16} \mathrm{Al}$ respecto, véase Trome v. Spain (demanda núm. 27781/95, 1 de abril de 1999), Rosival and others v. Slovakia (demanda núm. 17684/02, 23 de septiembre de 2008), Orha v. Romania (demanda núm. 1486/02, 4 de noviembre de 2008), Ercolani v. San Marino (demanda núm.35430/97, 25 de noviembre de 2003).
} 
presión - por parte del Estado, del TEDH o de la Secretaríapara que el demandante concluya un acuerdo. Es responsabilidad del Tribunal asegurarse de que tales circunstancias se produzcan de manera que el demandante debe estar suficientemente informado sobre las consecuencias que produce el acuerdo, para él y para su posición jurídica. El TEDH y la Secretaría deben asumir la esencial diferencia ontológica esencial entre Estado y demandante y subsanar, en la medida de sus posibilidades, las diferencias de información (KELLER, FOROWICZ, \& ENGI, 2010, pág. 95). Para subsanar tales deficiencias de información es relevante la llamada "obligación de advertencia" que algunas legislaciones nacionales contienen, y que contribuye a la igualación de las partes (por ejemplo, el $\S$ 139 de la Ley Procesal Civil alemana o el $\S 182$ de la Ley Procesal Civil austríaca, ambas conocidas como $Z P O) .{ }^{17}$

- La tercera y última cuestión que debe ser considerada en el canon de conformidad en sentido estricto, es si el acuerdo es respetuoso con la dignidad humana, tal como es concebida por derecho internacional (McCRUDDEN, 2008, pág. 656 y ss.) (KOTZMANN \& SEERY, 2017). En términos generales, se puede entender que no se respeta la dignidad humana cuando el ser humano queda degradado a la categoría de objeto. ${ }^{18}$ De esta manera, un acuerdo amistoso en el que la solución adoptada no sea respetuosa con la dignidad humana in abstracto no puede ser conforme con los derechos humanos. La relación basilar entre el derecho a la vida y la dignidad humana queda explicitada en el

\footnotetext{
${ }^{17}$ En Austria se conoce la función como Manuduktionspflicht (del latín manus, mano, y ductus, liderazgo), y supone, para el Estado, la obligación de información y aclaración a los interesados de sus derechos. En Alemania se la conoce como Hinweispflicht (obligación de advertencia). En España, mutatis mutandis, véase el art. 429.1.III LEC. ${ }_{18} \mathrm{Al}$ respecto pueden verse las siguientes resoluciones del Tribunal Constitucional alemán: BVerfGE 36, 375, de 12 de noviembre de 1997; BVerfGE 45, 187, de 21 de junio de 1977 y la más reciente BVerfGE 115, 11, de 15 de febrero de 2006. Una exposición histórica del concepto constitucional - relevante para el CEDH - de dignidad humana puede verse en MASFERRER (MASFERRER, 2017, pág. 494 y ss.).
} 
Preámbulo del Protocolo núm. 13, relativo a la abolición de la pena de muerte en cualquier circunstancia. Al margen de la discusión sobre el valor normativo de los preámbulos, ${ }^{19}$ lo cierto es que allí se señala que "el derecho de toda persona a la vida es un valor fundamental en una sociedad democrática, y de que la abolición de la pena de muerte es esencial para la protección de este derecho y el pleno reconocimiento de la dignidad inherente a todo ser humano". Una transacción sobre el derecho a la vida o a la prohibición de tortura no es [conforme con] el pleno reconocimiento de la dignidad inherente a todo ser humano y debe ser rechazada.

Si el resultado de estas comprobaciones es positivo, se puede afirmar que el acuerdo es internamente respetuoso con los derechos humanos en la manera en que son concebidos por el Convenio y por sus Protocolos.

\section{b. Conformidad en sentido amplio}

Ahora bien, que el acuerdo esté justificado internamente no quiere decir que sea oportuno desde un punto de vista externo. El canon de oportunidad de la conformidad o conformidad en sentido amplio se construye, como se ha dicho anteriormente, sobre la base de consideraciones externas al sistema del CEDH. Algunos de los criterios sobre los que puede construirse el canon de oportunidad de la conformidad son los siguientes:

- La primera cuestión que se plantea es si el acuerdo amistoso priva al demandante de otros derechos de relevancia en la vía

\footnotetext{
${ }^{19} \mathrm{Al}$ respecto señaló muy tempranamente el Tribunal Constitucional que ni las rúbricas de los títulos de las leyes ni los preámbulos tienen valor normativo (SSTC 36/1981, de 19 de noviembre y 173/1998, de 23 de julio, por todas). Sí tienen, sin embargo, un valor interpretativo notable. Al respecto, puede verse CERDEIRA BRAVO DE MANSILLA (CERDEIRA BRAVO DE MANSILLA, 2015). El Tribunal Constitucional alemán sostuvo en sus inicios que "el preámbulo de la Ley Fundamental tiene una importancia principalmente política, pero también jurídica” (BVerfGE 5, 85, 85, 17 de agosto de 1956).
} 
interna. Si este es el caso, deberá analizarse con mayor cautela el acuerdo amistoso. En la legislación procesal española se plantean problemas en relación con el art. 510.2 de la Ley de Enjuiciamiento Civil (LEC) o con el art. 954.3 de la Ley de Enjuiciamiento Criminal (LECrim). El art. 510.2 LEC señala que: “se podrá interponer recurso de revisión contra una resolución judicial firme cuando el Tribunal Europeo de derechos humanos haya declarado que dicha resolución ha sido dictada en violación de alguno de los derechos reconocidos en el Convenio Europeo para la Protección de los Derechos Humanos y Libertades Fundamentales y sus Protocolos". El tenor literal del precepto no permitiría la revisión de una sentencia dictada en el orden interno, si el acuerdo amistoso ante el TEDH no declarase que se ha producido "violación en alguno de los derechos reconocidos en el Convenio". Lo cierto es que son contadas las ocasiones en que los acuerdos amistosos reconocen vulneraciones de derechos. ${ }^{20}$ También es problemático el tenor literal del art. 512.1.II LEC, que se refiere a una "sentencia" del TEDH, lo que excluiría otra clase de resoluciones, como las decisiones del TEDH (que son la forma que toman las resoluciones del TEDH al aprobar los acuerdos amistosos) (FROWEIN, 1969, pág. 216). El mismo problema se plantea en otros países (SCHIARABBA, 2014). En definitiva, mientras no sea claro que el demandante puede servirse del juicio de revisión, el TEDH no debería archivar el asunto definitivamente (KARPENSTEIN, MAYER, \& WENZEL, 2015, par. 18). ${ }^{21}$

- En relación con el pago se plantean dos cuestiones. De un lado, "la compensación que se prevea en el acuerdo debe estar en la

\footnotetext{
${ }^{20}$ A veces, sin embargo, sucede que los Estados reconocen tales violaciones en los acuerdos amistosos. Véase, por ejemplo, Atashev and Atasheva v. Russia (demanda núm. 33727/14, 15 de noviembre de 2016), Centre for Legal Resources on behalf of Malacu and others $v$. Romania (demand anúm 55093/09, 27 de septiembre de 2016).

${ }^{21}$ Véase, además, Hakimi v. Belgium (demanda núm. 665/08, 6 de diciembre de 2011) y Rozhin v. Russia (demanda núm. 50098/07, 6 de marzo de 2012).
} 
debida proporción al daño que las partes han sufrido" (KELLER, FOROWICZ, \& ENGI, 2010, pág. 99). De otro lado, los pagos $e x$ gratia deben ser excepcionales. $\mathrm{O}$ bien se producen ex contractu o se producen ex obligatione. Es decir, se produce el pago porque existe un contrato de transacción que sustenta la pretensión del demandante de ser pagado o bien se produce porque el Estado reconoce su responsabilidad extracontractual (pero igualmente obligatoria) y paga lo convenido..$^{22}$ Sobre ello, el TEDH ha señalado que el pago ex gratia se puede asumir cuando va "combinado con un reconocimiento explícito de una violación del Convenio" (demanda núm. 32557/05, Mandic v. Montenegro, Serbia, Bosnia Herzegovina, 12 de junio de 2012) (ABDELGAWAD, 2018, pág. 14).

- La tercera cuestión que se plantea es si el acuerdo amistoso priva a la comunidad de un desarrollo jurisprudencial importante para la tutela de los derechos humanos de otros posibles demandantes. ${ }^{23}$ De esta manera, el acuerdo debe tener por objeto un asunto sobre el que la jurisprudencia del TEDH esté consolidada. En esta exigencia se manifiesta el componente objetivo del sistema de derechos del CEDH. La paz jurídica y el interés público exigen que le Tribunal no esté constreñido en el libre desarrollo de su jurisprudencia. El TEDH ya ha afirmado que un acuerdo es respetuoso con el interés público cuando se inspira en la jurisprudencia del Tribunal (Vallon v. Italy, demanda núm. 9621/81, 3 de junio de 1985). ${ }^{24}$ Algunos autores han criticado, con razón, los acuerdos amistosos en materias

\footnotetext{
$22 \mathrm{El} \mathrm{TEDH}$ se ha pronunciado al respecto en Prencipe v. Mónaco (demanda núm. 43376/06, 16 de julio de 2009).

${ }^{23}$ Sobre la cuestión, véase ZWAAK (ZWAAK, 2006, pág. 225). Allí se señala que el TEDH no invitará a las partes a alcanzar un acuerdo amistoso en los casos en que "una decisión sobre el fondo es importante para el futuro desarrollo de la jurisprudencia". Ver también BRATZA y O’BOYLE (BRATZA \& O’BOYLE, 1998, pág. 387).

${ }^{24} \mathrm{El}$ interés general puede satisfacerse incluso si el Estado no reconoce haber violado el Convenio (Hurtado v. Switzerland, demanda núm. 17549/90, 28 de enero de 1994).
} 
novedosas, pues producen una "infraproducción de decisiones y precedentes” (KELLER, FOROWICZ, \& ENGI, 2010, pág. 95).

- Por último, se plantea si los hechos son o no controvertidos. De serlo, ello es un indicio en contra de la aceptación del acuerdo amistoso, pues el restringido poder de disposición de las partes se extiende al contenido del acuerdo, no a la fijación de los hechos, como se ha visto anteriormente. Esto es responsabilidad última del Tribunal (KARPENSTEIN, MAYER, \& WENZEL, 2015, par. 25).

\section{c. Recapitulación}

Esta es la teoría. Sin embargo, la práctica demuestra que el TEDH ha continuado con el examen de un caso de manera excepcional (The European Human Rights Advocacy Centre at Middlesex University, 2018, pág. 7). Ello puede tener dos significados: o bien los acuerdos amistosos que se plantean en la práctica son siempre, o casi siempre, conformes con los derechos humanos, o bien que el TEDH, generalmente, renuncia a hacer mayores comprobaciones. En ambas afirmaciones hay verdad. A ello debe sumársele una cierta inercia institucional, pues la anterior Comisión nunca rechazó un acuerdo por no ser conforme con los derechos humanos (quizás porque su intervención en las negociaciones era tan intensa, que nunca se formalizaban acuerdos que no fueran a ser aceptados posteriormente). El TEDH, en su configuración actual, sí ha rechazado acuerdos por no ser conformes con los derechos humanos. $^{25}$

${ }_{25}$ Tyrer v. United Kingdom (demanda núm. 5856/72, 25 de abril de 1978), Tehrani and others v. Turkey (demandas núm. 32940, 41626 y 43616/08, 13 de abril de 2010), Ukranian Media Group v. Ukraine (demanda núm. 72713/01, 29 de marzo de 2005), Gagiu v. Romania (demanda núm. 63258/00, 24 de febrero de 2009). 


\section{Equidad del acuerdo}

Las consideraciones realizadas anteriormente sobre la conformidad con los derechos humanos pueden extenderse, mutatis mutandis, a la equidad del acuerdo. Sin embargo, su importancia práctica es reducida. Pocas resoluciones del TEDH hacen siquiera mención de la necesaria equidad del acuerdo. ${ }^{26}$ El anclaje normativo de la exigencia de equidad se encuentra en el art. 75.4 RTEDH. Este dispone que:

si el Tribunal es informado de que se ha llegado a un acuerdo entre la parte perjudicada y la Parte Contratante responsable, verificará el carácter equitativo del acuerdo y, cuando considere que el acuerdo es equitativo, archivará la demanda de conformidad con el art. 43.3 RTEDH.

Respecto de la equidad es posible mantener dos posturas. De una parte, es posible entender que la equidad es un elemento esencial de la conformidad con los derechos humanos, de manera que una no es posible sin la otra. Esta postura explica un tratamiento conjunto de ambos fenómenos; equidad y conformidad con los derechos humanos serían expresión de una misma esencia: la adecuación del acuerdo al Convenio. De otro lado, es posible sostener que equidad y conformidad con los derechos humanos son esencialmente diferentes. Ello se sustenta en que la equidad está intrínsecamente unida (no solo literalmente) con la satisfacción equitativa del art. 41. CEDH. Sin embargo, este precepto queda normalmente fuera del ámbito de aplicación de los acuerdos amistosos, pues exige que el Tribunal declare una violación del Convenio. Ello, como se ha visto anteriormente, es excepcional en la práctica de los acuerdos amistosos. De esta manera, si la equidad del art. 75.4 RTEDH y la

\footnotetext{
${ }^{26}$ No hacen referencia alguna a la equidad, por ejemplo, Suldin and others $v$. Russia (demanda núm. 48901/18, 9 de julio de 2020), Ehik and Dascălu v. Romania (demandas núm. 62010 y 62756/16, 9 de julio de 2020), Grigoryev and others v. Russia (demanda núm. 14314/18, 9 de julio de 2020), o Mitić v. Serbia (demanda núm. 6109/19, 9 de julio de 2020).
} 
satisfacción equitativa del art. $41 \mathrm{CEDH}$ son esencialmente idénticas, no es posible afirmar que también lo es la conformidad con los derechos humanos del art. 39.1 CEDH. Ello por la siguiente razón: si los arts. $41 \mathrm{CEDH}$ y 75.4 RTEDH forman una equidad en sentido amplio, y esta no es considerada en la mayoría de los acuerdos amistosos (porque el art. $41 \mathrm{CEDH}$ queda excluido), no es posible afirmar que la equidad forme parte de la conformidad con los derechos humanos.

\section{Conclusiones}

Los acuerdos amistosos reservan para todos los intervinientes grandes ventajas: desde satisfacer rápida y eficazmente los intereses del demandante, hasta evitar el estigma para el Estado de ser condenado por una vulneración de derechos humanos, sin olvidar la reducción de la carga de trabajo de la Corte. Sin embargo, existen densas sombras que circundan la institución, desde los nebulosos límites objetivos que (des)dibujan el CEDH y el RTEDH — con la aquiescencia, antes de la Comisión, y hoy de la Corte- hasta su riesgo de abuso. Tampoco se pueden soslayar los problemas relacionados con el Estado de Derecho y la separación de poderes, pues los representantes de los Estados ante el TEDH carecen de legitimidad directa para obligarse, por ejemplo, a modificar legislaciones o prácticas administrativas ajenas a su competencia. No obstante, algunos de estos problemas se pueden solventar parcialmente.

De un lado, la ausencia de límites objetivos claros en el CEDH y en el RTEDH se puede colmar mediante diversos recursos. Por una parte, es posible asumir la tendencia jurisprudencial de la Corte Interamericana de Derechos Humanos (Velásquez v. Honduras, 26 de junio de 1989) y excluir los acuerdos amistosos en los supuestos de vulneraciones a los arts. 2 y $3 \mathrm{CEDH}$. De otro lado, es posible incluir en el CEDH, preferiblemente, (o en el RTEDH, como solución provisional) alguna clase de criterios que permitan objetivizar el test de conformidad con los derechos humanos, de modo que la práctica 
del TEDH sea unitaria y homogénea. En cuanto al ámbito objetivo, es preciso también establecer límites a los acuerdos amistosos cuando estos pretenden resolver asuntos sobre los que no existe jurisprudencia consolidada de la Corte. Tales límites favorecen el carácter objetivo de los derechos humanos que, como se ha dicho antes, no son solo derecho subjetivo del demandante, sino valores del ordenamiento internacional que deben ser desarrollados. A estos efectos, debe producirse una mejora en los sistemas de publicidad de los acuerdos amistosos de manera que, por ejemplo, cuando versen sobre asuntos de interés general (a pesar de la dificultad que su definición conlleva) sean publicados en el Boletín Oficial del Estado (CONTESSE, 2019, pág. 370 y ss.).

Finalmente, deben arbitrarse los mecanismos necesarios para aminorar, en la medida de lo posible, la desigualdad natural existente entre el Estado y el demandante. De un lado, podría construirse una obligación de realizar advertencias — como ya realizan algunas legislaciones procesales nacionales - para los jueces de la Corte. De esta manera, la Corte quedaría obligada a poner de manifiesto a las partes (especialmente a la más débil) las implicaciones del recurso a los acuerdos amistosos. Por último, debe objetivizarse e interpretarse más restrictivamente la posibilidad abierta a los Estados de recurrir a las declaraciones unilaterales como medio de terminación del proceso, cuando las negociaciones amistosas fallan. Obligar a los Estados a reconocer su responsabilidad en las declaraciones unilaterales constituye un paso muy relevante, otro más debe ser obligar a los Estados a indemnizar con mayores cuantías. Ello podría ser una tentación para los demandantes de evitar toda clase de negociación amistosa para forzar al Estado a una declaración unilateral y recibir una indemnización mayor. Sin embargo, este riesgo puede asumirse, máxime cuando la Corte y la Secretaría están al corriente e intervienen en las negociaciones.

En definitiva, los acuerdos amistosos y otros mecanismos análogos de resolución de conflictos reservan muy importantes ventajas para los intervinientes. No obstante, urge que el TEDH 
concrete su ámbito objetivo de aplicación, en beneficio no solo de demandantes, sino de toda la comunidad sometida al CEDH.

\section{Referencias}

ABDELGAWAD, L. (2018). The practice of the European Court of Human Rights when striking out applications. Netherlands Quarterly of Human Rights, 36.

ALEXY. (2015). Grundrechte, Demokratie und Repräsentation. Der Staat, 54(2).

BRATZA, \& O'BOYLE. (1998). The legacy of the Comission to the New Court under the Protocol No.11. In DE SALVIA, \& VILLIGER, L'éclosion du Droit européen des Droits de l'Homme en Liber Amicorum Carl Aage Nørgaard. Nomos Verlaggesellschaft.

CERDEIRA BRAVO DE MANSILLA. (2015). Principio, realidad y norma: el valor de las exposiciones de motivos (y de los preámbulos). México D.F. y Madrid: Editorial Ubijus.

CONTESSE. (2019). Settling Human Rights Violations. Harvard International Law Journal, 60.

CUCARELLA GALIANA. (2019). Derecho a la igualdad, prohibición de discriminación y Jurisdicción. Madrid: Wolters Kluwer.

EPPING. (2019). Grundrechte. Berlín: Springer.

FROWEIN. (1969). Der freundschaftliche Ausgleich im Individualbeschwerdeverfahren nach der Menschenrechtskonvention und das deutsche Recht. Juristenzeitung (7).

GRABENWARTER, \& PABEL. (2016). Europäische Menschenrechtskonvention. C.H. Beck.

KARPENSTEIN, MAYER, \& WENZEL. (2015). EMRK. CHBeck. 
KELLER, FOROWICZ, \& ENGI. (2010). Friendly settlements before the European Court of Human Rights: Theory and Practice. Oxford: Oxford University Press.

KLATT, \& MEISTER. (2014). Der Grundsatz der Verhältnismäßigkeit. In KLATT, \& MEISTER, Juristische Schulung (JuS). Beck.

KOTZMANN, \& SEERY. (2017). Dignity in International Human Rights Law: Potential Applicability in relation to International Recognition of Animal Rights. Michigan International Law Review, 26.

KRÜGER, H., \& NØRGAARD, C. (1988). Reflections concerning friendly settlement under the European Convention of Human Rights. In M. F. H., Protecting Human Rights: the European dimension: studies in honour of Gerard J. Wiarda. Carl Heymanns Verlag KG.

LARENZ, \& CANARIS. (1995). Methodenlehre der Rechtswissenschaft. Springer.

MASFERRER. (2017). Una historia retrospectiva de la dignidad humana. Glossae: European Journal of Legal History (14).

McCRUDDEN. (2008). Human Dignity and Judicial Interpretation of Human Rights. The European Journal of International Law, $19(4)$.

MIR PUIG. (2016). Derecho Penal Parte General. Barcelona: Reppertor.

SCHIARABBA. (2014). La riapertura del giudicato a seguito di sentenze della Corte di Strasburgo: il ruolo della comparazione. Europeanrights Newsletter.

The European Human Rights Advocacy Centre at Middlesex University. (2018). Guide to friendly settlements and unilateral declarations before the European Court of Human Rights. Londres.

WEBER, G. (2007). Who Killed the Friendly Settlement? The Decline of Negotiated Resolutions at The European Court of Human Rights. Pepperdine Dispute Resolution Law Journal, 7 (2), 235. 
Revista Internacional de Derechos Humanos / E-ISSN 2422-7188 / 2021 Vol. 11, No. 1 revistaidh.org

ZWAAK, L. (2006). In P. e. VAN DIJK, Theory and Practice of the ECHR. Intersentia. 